\title{
ANALYSIS OF CAESAREAN SECTION AETIOLOGY IN A RURAL MEDICAL COLLEGE- A RETROSPECTIVE STUDY
}

\author{
Gurneesh Singh ${ }^{1}$, Alka Chhabra²
}

${ }^{1}$ Associate Professor, Department of Obstetrics \& Gynaecology, Maharaja Agrasen Medical College, Agroha, Hisar. ${ }^{2}$ Senior Professor and HOD, Department of Obstetrics \& Gynaecology, Maharaja Agrasen Medical College, Agroha, Hisar.

\begin{tabular}{l}
\hline ABSTRACT \\
BACKGROUND \\
Caesarean section (CS) is the most commonly performed surgery in obstetrical care. The WHO stated, in 2015, that every effort \\
should be made to provide CS to women in need, rather than striving to achieve a specific rate.[1] The prevalence of CS has increased \\
fastest among rural, poor and less educated women.[2] \\
$\quad$ To compare the rise in institutional deliveries with rise in CS (Caesarean Section) in a rural medical college and analyse trends.
\end{tabular}

\section{MATERIALS AND METHODS}

All delivery records of a rural medical college during 6 years period from Jan. 2010 to Dec. 2015 were examined and data of all deliveries including CS was collected and analysed. Statistical analysis was done using regression analysis for generalised linear regression for changes in incidence and indications.

\section{RESULTS}

Over 6 years, annual number of deliveries in rural college increased from 285 to 2209 (775\% rise). CS rates increased from 113 to 1224 (1083\% rise). Total no. of consultants and paramedical staff remained same. This rise in CS rate when compared with rise in total deliveries was found to be statistically highly significant $(\mathrm{p}<0.0001)$. Amongst the indications, increase in CS rate was mainly due to increase in post-CS pregnancies (26.17\%-41.457\%), non-progress of labour (NPOL) (7.56\%-17.32\%) and foetal distress (5.31\%-22.9\%).

\section{CONCLUSION}

Rapid rise in institutional deliveries increases the CS rates. Rise in CS rate in this study was found statistically highly significant. Postcaesarean pregnancy, non-progress of labour and foetal distress were the largest contributors for CS.

\section{KEYWORDS}

Caesarean Section, Indication, Post-Caesarean Pregnancy, Rural Medical College, Institutional Deliveries.

HOW TO CITE THIS ARTICLE: Singh G, Chhabra A. Analysis of caesarean section aetiology in a rural medical college- A retrospective study. J. Evolution Med. Dent. Sci. 2016;5(86):6409-6411, DOI: 10.14260/jemds/2016/1449

\section{BACKGROUND}

Caesarean section (CS) is the most commonly performed surgery in obstetrical care. It can be life-saving and is also a highly effective procedure for preventing adverse effects of complications such as dystocia, foetal distress, APH, etc. The WHO stated, in 2015, that every effort should be made to provide CS to women in need, rather than striving to achieve a specific rate.[1] Although overall total caesarean section in world is estimated around 15\%, caesarean section rates seem to vary by education, country, states within a country, type of facility (private versus public) and level and type of caregiver, workload, etc. The prevalence of CS has increased fastest among rural, poor and less educated women.[2] Caesarean section rate may be influenced by non-medical factors, e.g. ability to pay, fear of litigation, convenience, perceived safety, fear of substandard care and the opportunity for sterilisation.[3,4]

Financial or Other, Competing Interest: None.

Submission 28-07-2016, Peer Review 15-10-2016,

Acceptance 22-10-2016, Published 27-10-2016.

Corresponding Author:

Dr. Gurneesh Singh,

Associate Professor,

Department of Obstetrics \& Gynaecology,

Maharaja Agrasen Medical College,

Agroha, Hisar.

E-mail: gurneeshellora@yahoo.co.in

DOI: $10.14260 /$ jemds/2016/1449
Government's emphasis on deliveries attended by doctors rather than midwives may also have contributed especially in public health facilities.

\section{MATERIALS AND METHODS}

Retrospective analysis of all the delivery records of births during 6 years period from Jan. 2010 to Dec. 2015 was done and data of CS was analysed. Statistical analysis was done using regression analysis for generalised linear regression for changes in incidence and indications.

\section{RESULTS}

Over the years, annual number of deliveries increased approx. $50.6 \%$ per year totalling $775 \%$ from 285 (2010) to 2209 (2015) as shown in Table 1. In the corresponding period, CS delivery rates rose approx. $61.05 \%$ annually totalling $1083 \%$ from 113 (39.65\%) to 1224 (55.41\%). Table 1 shows number of total deliveries and CS and its percentage. This rise in CS delivery was found statistically highly significant $(p<0.0001)$.

\begin{tabular}{|c|c|c|c|c|}
\hline Year & $\begin{array}{c}\text { Total } \\
\text { CS }\end{array}$ & $\begin{array}{c}\text { Total } \\
\text { Deliveries }\end{array}$ & $\begin{array}{c}\text { \% Rise } \\
\text { CS }\end{array}$ & $\begin{array}{c}\text { \% Rise } \\
\text { Total del }\end{array}$ \\
\hline 2010 & 113 & 285 & 100 & 100 \\
\hline 2011 & 275 & 595 & 143.36 & 108.77 \\
\hline 2012 & 354 & 691 & 213.27 & 142.45 \\
\hline 2013 & 489 & 926 & 332.74 & 224.91 \\
\hline 2014 & 755 & 1368 & 568.14 & 380 \\
\hline 2015 & 1224 & 2209 & 983.18 & 675.08 \\
\hline \multicolumn{7}{|c|}{} \\
Table 1. Number of Total Deliveries and CS and their \\
\% Age Rise annually taking year 2010 as Baseline \\
\hline
\end{tabular}


Table 2 shows most common indications of CS, their frequency and percentage contribution to total CS in the rural medical college.

\begin{tabular}{|c|c|c|c|c|c|c|c|c|}
\hline Year & Post CS & NPOL & $\begin{array}{c}\text { Foetal } \\
\text { Distress }\end{array}$ & Breech & PIH & APH & CPD & Others \\
\hline 2010 & $\begin{array}{c}46 \\
(40.71 \%)\end{array}$ & $\begin{array}{c}14 \\
(12.39 \%)\end{array}$ & $\begin{array}{c}6 \\
(5.31 \%)\end{array}$ & $\begin{array}{c}17 \\
(15.04 \%)\end{array}$ & $\begin{array}{c}4 \\
(3.54 \%)\end{array}$ & $\begin{array}{c}11 \\
(9.73 \%)\end{array}$ & $\begin{array}{c}3 \\
(2.65 \%)\end{array}$ & $\begin{array}{c}12 \\
(10.62 \%)\end{array}$ \\
\hline 2011 & $\begin{array}{c}114 \\
(40.45 \%)\end{array}$ & $\begin{array}{c}41 \\
(14.90 \%)\end{array}$ & $\begin{array}{c}27 \\
(9.81 \%)\end{array}$ & $22(8.00 \%)$ & $\begin{array}{c}10 \\
(3.63 \%)\end{array}$ & $\begin{array}{c}29 \\
(10.54 \%)\end{array}$ & $\begin{array}{c}11 \\
(4.00 \%)\end{array}$ & $21(7.63 \%)$ \\
\hline 2012 & $\begin{array}{c}105 \\
(29.66 \%)\end{array}$ & $\begin{array}{c}90 \\
(25.42 \%)\end{array}$ & $\begin{array}{c}43 \\
(12.14 \%)\end{array}$ & $\begin{array}{c}40 \\
(11.30 \%)\end{array}$ & $\begin{array}{c}17 \\
(4.80 \%)\end{array}$ & $\begin{array}{c}21 \\
(5.93 \%)\end{array}$ & $\begin{array}{c}18 \\
(5.08 \%)\end{array}$ & $\begin{array}{c}20 \\
(5.65 \%)\end{array}$ \\
\hline 2013 & $\begin{array}{c}128 \\
(26.17 \%)\end{array}$ & $\begin{array}{c}37 \\
(7.56 \%)\end{array}$ & $\begin{array}{c}112 \\
(22.90 \%)\end{array}$ & $\begin{array}{c}66 \\
(13.49 \%)\end{array}$ & $\begin{array}{c}50 \\
(10.22 \%)\end{array}$ & $\begin{array}{c}21 \\
(4.29 \%)\end{array}$ & $\begin{array}{c}8 \\
(1.63 \%)\end{array}$ & $\begin{array}{c}67 \\
(13.70 \%)\end{array}$ \\
\hline 2014 & $\begin{array}{c}239 \\
(31.65 \%)\end{array}$ & $\begin{array}{c}72 \\
(9.53 \%) \\
\end{array}$ & $\begin{array}{c}134 \\
(17.74 \%) \\
\end{array}$ & 75 (9.93\%) & $\begin{array}{c}72 \\
(9.53 \%) \\
\end{array}$ & $\begin{array}{c}29 \\
(3.84 \%) \\
\end{array}$ & $\begin{array}{c}23 \\
(3.04 \%) \\
\end{array}$ & $\begin{array}{c}111 \\
(14.70 \%)\end{array}$ \\
\hline 2015 & $\begin{array}{c}409 \\
(33.41 \%) \\
\end{array}$ & $\begin{array}{c}212 \\
(17.32 \%) \\
\end{array}$ & $\begin{array}{c}129 \\
(10.93 \%) \\
\end{array}$ & $\begin{array}{c}136 \\
(11.11 \%) \\
\end{array}$ & $\begin{array}{c}140 \\
(11.44 \%)\end{array}$ & $\begin{array}{c}54 \\
(4.41 \%) \\
\end{array}$ & $\begin{array}{c}54 \\
(4.41 \%) \\
\end{array}$ & $\begin{array}{c}90 \\
(7.35 \%) \\
\end{array}$ \\
\hline
\end{tabular}

Chart 1 shows number of total deliveries and CS and percentage rise of CS as compared to \% rise in total deliveries from 2010-2015 as shown in tables 1.

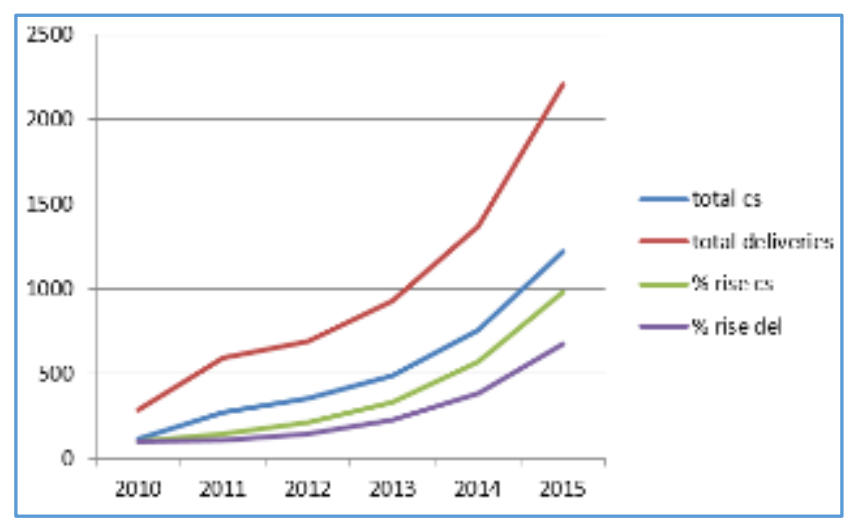

Chart 1. Number of Total Deliveries and CS and $\%$ Age Rise as compared to Baseline 2010

Chart 2 shows proportion of common indications of CS over the years as shown in Table 2 .

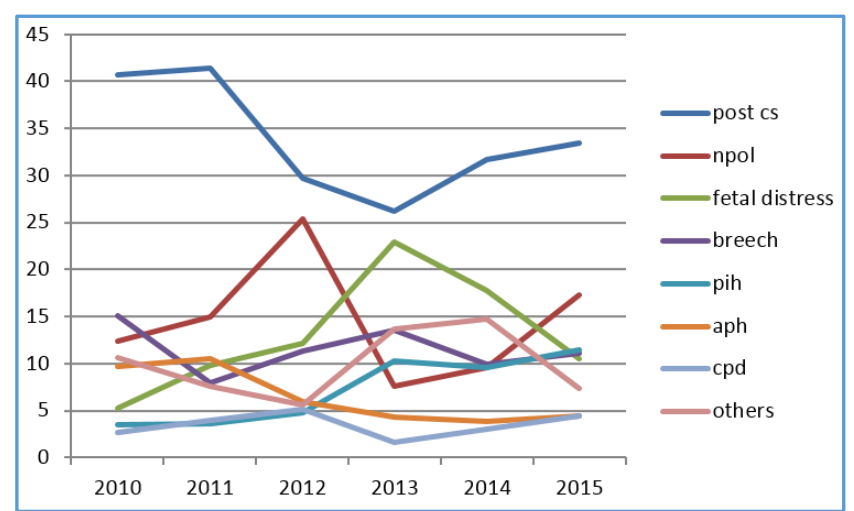

Chart 2. Percentage Contribution of Common Indications of CS from 2010-2015

Chart 3 and chart 4 show regression analyses with total deliveries and percentage rise in total deliveries in $\mathrm{X}$ axis and CS and percentage rise in CS in $\mathrm{Y}$ axis showing generalised linear regressions.

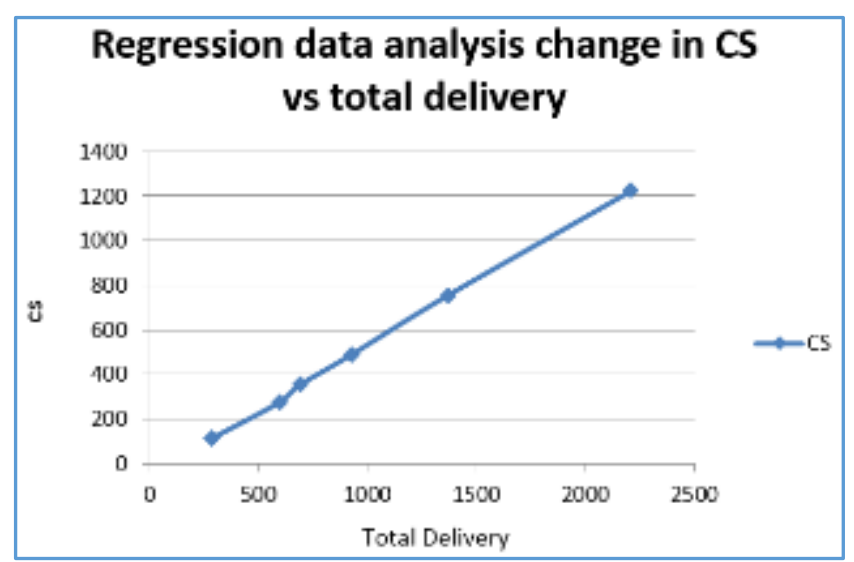

Chart 3

Statistical analysis of chart 3 shows best fit value of slope $0.5818 \pm 0.0077$ (95\% confidence limit 0.5602 to 0.6034 ) with goodness of fit 0.9993 and $P$ value $<0.0001$ showing significant deviation from horizontal. Probability of $\mathrm{Y}=0.5818^{*} \mathrm{X}-54.00$.

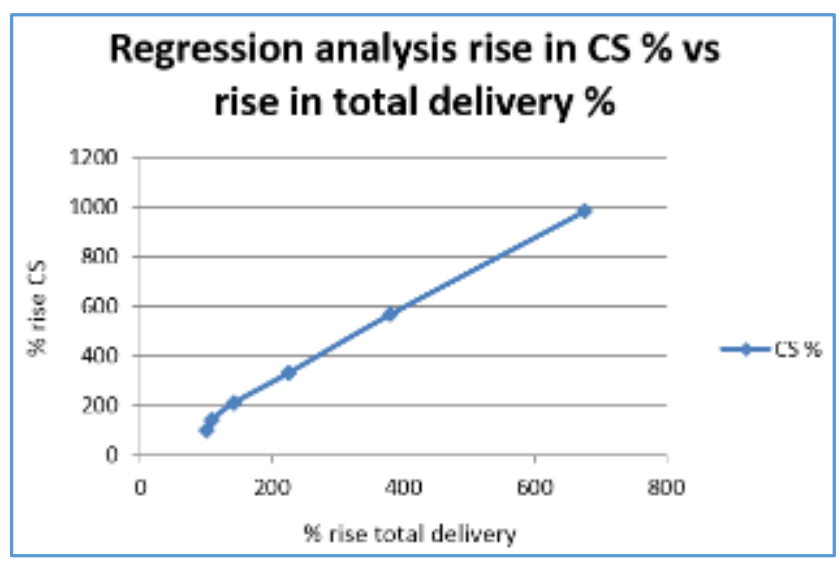

Chart 4

Statistical analysis of chart 3 shows best fit value of slope $1.500 \pm 0.0437$ (95\% confidence limit 1.379 to 1.621 ) with goodness of fit 0.9966 and $P$ value $<0.0001$ showing significant deviation from horizontal. Probability of $\mathrm{Y}=1.500 * \mathrm{X}-17.71$. 


\section{DISCUSSION}

Estimates of CS rates in India was 2.7\% (NFHS1 92-93), 7.1\% (NFHS2 98-99), 10.6\% (NFHS3 05-06) and 24.53\% (NFHS4 phase 1 average estimate 2015-16) and showing 10.1\% increase in the rates annually in India. CS rate is much higher (30-69.9\%) in tertiary care hospitals and teaching hospitals. ${ }^{[5-8]}$ In our study, CS rate was $39.65 \%-55.41 \%$. It appears very high considering the $10.6 \%$ (rural) $-13.6 \%$ (urban) CS rate for Haryana.[9] However, in Haryana, with increase in institutional deliveries from $35.7 \%$ (NFHS3) to $80.5 \%$ (NFHS4), CS rate has more than doubled from $5 \%$ (NFHS3) to $13.38 \%$ (NFHS4). In India, many women deliver at home due to lack of access to better facilities. Many despite of requiring $\mathrm{CS}$, are forced to undergo normal delivery resulting in maternal and perinatal complications. The rural areas in most parts of India do not have facility for conducting even a normal delivery. Only 13.1\% CHC in Haryana were posted with obstetrician and most of them are located in urban areas.[10] Many delivery complications can be handled efficiently initially by normal delivery, but if over looked, later require CS e.g. PIH etc. This is a vital reason for which the caesarean section is more in tertiary care institutions. In Haryana, complete Ante natal care is available only to $18.3 \%$ women in rural areas. ${ }^{[9]}$ The emergency obstetric care provided to the patients is not uniform over the geographical spread. It is different for urban and rural regions and it is even different for different states of India. In the states with high level of urbanisation and literacy and higher level of antenatal and institutional care, CS rate is higher in both rural and urban areas e.g. Telangana ( $53.4 \%$ vs. $63.2 \%$ ), Tamil Nadu (32.3\% vs. $36.1 \%) .[9]$

With rapid increase in institutional deliveries in recent years due to improvement of socioeconomic conditions, level of education, enhanced advocacy for institutional deliveries in India [34\% (DLHS, 1998-99); 47\% (DLHS, 2007-08); 60.5\% (SRS, 2010)], easy access to communication and free transport facilities under National Rural Health Mission (NRHM), the other aspect of this scenario also points out at rising occupational burden, stress and sleep deprivation amongst health professionals especially if accompanied by staff shortage in public tertiary health institutions. This leads to low threshold for CS whenever need for close intrapartum monitoring arises in high risk pregnancies. All complicated cases which can't be handled at primary and secondary levels are also sent to tertiary centres increasing operative interventions.

The commonest indication for CS in this series was post-CS pregnancy $33.22 \%(24.3 \%-41.45 \%)$, followed by nonprogress of labour $16.11 \%$ (9.54\%-25.42\%), foetal distress $12.96 \%$ (5.31\%-22.91\%), breech presentation $11.99 \%$ (8\%$15.04 \%)$ and PIH $6.71 \% \quad(3.81 \%-11.43 \%)$, antepartum haemorrhage $\quad 6.64 \% \quad(3.84 \%-10.55 \%)$, cephalopelvic disproportion $4.16 \%(1.64 \%-6.43 \%)$. Other studies have also shown similar results.[5,7,11]

Incidence of post-CS pregnancy contributing to CS is very high in this study as compared to other factors. Recent studies all over world have shown post-CS pregnancy as the main factor in rise of CS.[5,11] Due to many steps taken by institution to reduce total number of CS, many cases of post CS pregnancies and other high risk pregnancies like meconium stained liquor, PIH, twins, breech, etc. were offered trial of labour leading to sharp increase in non-progress of labour cases in 2015.

Despite of conscious efforts by institution to reduce the rate of CS, incidence is quite high. Due to paucity of safe delivery facilities and non-availability of gynaecologist in surrounding areas around the clock, more and more pregnant ladies are opting for this institution and almost all complicated cases are being referred to this institution. As treatment of all pregnant cases including deliveries and CS is totally free with low maternal and foetal morbidity and mortality, it may also have led to rapid rise in total deliveries and CS.

\section{CONCLUSION}

This study shows that rapid rise in institutional deliveries increases the CS rates. Rise in CS rate in this study was found statistically highly significant with post-caesarean pregnancy, NPOL (non-progress of labour) and foetal distress being the largest contributors.

\section{REFERENCES}

1. World Health Organization. WHO statement on caesarean section rates, 2015. WHO/RHR/15.02.

2. Feng $\mathrm{XL}, \mathrm{Xu} \mathrm{L}$, Guo $\mathrm{Y}$, et al. Factors influencing rising caesarean section rates in China between 1988 and 2008. Bulletin of the World Health Organization 2012;90:30-9A.

3. Harris A, Gao Y, Barclay L, et al. Consequences of birth policies and practices in post-reform China. Reprod Health Matters 2007;15(30):114-24.

4. Mazzoni A, Althabe F, Liu NH, et al. Women's preferences for caesarean section: a systematic review and metaanalysis of observational studies. BJOG 2011;118(4):3919.

5. Barber EL, Lundsberg LS, Belanger $\mathrm{K}$, et al. Indications contributing to the increasing caesarean delivery rate. Obstetrics Gynecol 2011;118(1):29-38.

6. Rami Al Rifai. Rising cesarean deliveries among apparently low-risk mothers at university teaching hospitals in Jordan: analysis of population survey data, 2002-2012. Glob Health Sci Pract 2014;2(2):195-209.

7. Elkhayat W, Adel D, El-Bar MA, et al. Cesarean section rate at a tertiary university hospital in Egypt in five years period (2008 -2012). KAJOG 2013;4(3):66-74.

8. Kozhimannil KB, Law MR, Virnig BA. Cesarean delivery rates vary tenfold among US hospitals; reducing variation may address quality and cost issues. Health Aff (Millwood) 2013;32(3):527-35.

9. National Family Health Survey 4, India 2015-16.

10. District level household and facility survey, India 20072008.

11. Stasieluk A, Langowicz I, Kosińska-Kaczyńska K, et al. Is the epidemic of cesarean sections the result of more liberal indications. Ginekol Pol 2012;83(8):604-8. 